\title{
Design and Implementation of a Time-based Sun Tracking Solar System
}

\author{
Fahad Bin Ali ${ }^{1, a)}$, Rock Chakma ${ }^{2, b)}$, Ahamed Raihan, ${ }^{3, c),}$ Mahedi Hasan ${ }^{4, d), ~ M ~}$ \\ F Shahriar Khan ${ }^{1, \mathrm{e}),}$ M. J. Alam ${ }^{5, \mathrm{f})}$,Rupa Akter $^{6, \mathrm{~g})}$ and S. S. Mahtab ${ }^{5, \mathrm{~h})}$ \\ ${ }^{1}$ Department of Electrical and Computer Engineering, South China University of Technology, China. \\ ${ }^{2}$ Department of EEE, University of Science and Technology Chittagong, Chittagong, Bangladesh. \\ ${ }^{3}$ Department of CSE, Jahangirnagar University, Bangladesh. \\ ${ }^{4}$ BASc, Marine Engineering ,AMC (Australian Maritime College), University of Tasmania. \\ ${ }^{5}$ Department of EEE, Feni University, Trunk Road, Feni, Bangladesh. \\ ${ }^{6}$ Department of EEE, Mymensingh Engineering College, Mymensingh, Bangladesh.. \\ a) fahadbinali97@gmail.com \\ b) rocky.cht@gmail.com \\ c) araihan13@gmail.com \\ d)mahedih@utas.edu.au \\ e) shahariar55@gmail.com \\ f) alameee1993@g mail.com \\ g)rupa.mec.eee.bd@gmail.com

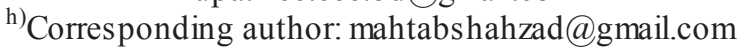

\begin{abstract}
Because of continuous decrease fuel of fossil reserve in earth, the whole world is now turning to renewable energy sources like solar, wind, geothermal, hydropower etc. In addition, it can be said that the ultimate source of energy on earth is sun with a few exceptions. And it is also the cleanest energy source without any pollution. The power value of $1.74 \times 1017$ watts receives by earth and the world consumes about $1.2 \times 1013$ watts of power per day. We are attempting to devour more energy from the sun utilizing the panel of solar. Changing of solar energy from electrical energy is expanding where the panels position of solar is situated vertically from the sun. In this way, the sun's tracking location and the panels position of solar is significant. In this paper, a new design of automatic tracking system to track the position of sun's has been focused. Though it is positioned vertically from the sun for the maximum conversion of energy in every times as move as solar panel with this system. In this tracking system, Light Depending Resistors (LDR) are applied as sensors. This system includes a microcontroller, LDR, gear motor system, and solar panels. This system is designed as dual axis tracking system. We also added a Real Time Clock and limit switch to reset the position of the solar panels at the end of the day.
\end{abstract}

Third International Conference on Material Science, Smart Structures and Applications AIP Conf. Proc. 2327, 020024-1-020024-9; https://doi.org/10.1063/5.0040001 Published by AIP Publishing. 978-0-7354-4071-5/\$30.00 


\section{INTRODUCTION}

Bangladesh is an agricultural country. Here mostly $70 \%$ peoples are directly or indirectly connected to the agriculture system, which most of them are very poor. That's why we are making an automatic system for the farmers which reduce their cost and time and improve their life styles.

During the previous couple of years, the solar power which is included in the renewable resources have gained much importance altogether over the world. Hydropower, biomass energy and wind generation are the different types of green energy or renewable resources which are utilizing availability to fulfill the demand of energ y. The resource of sustainable energy is as essential and prerequisite as solar energy along with the traditional renewable energy sources $[1,2,3]$. In light of its neatness, pervasiveness, bounty, and sustainability, solar energy-bas ed vitality has gotten very much perceived and generally used [4]. The estimation of few researches $0.16 \%$ covering through $10 \%$ proficient solar systems of conversion which would give power of intensity value is $20 \mathrm{TW}$, the energy of fossil utilization pace in this twice world's approximately[5]. Solar energy is capable of the demonstrates which successively needed for pointing out of the tracking apparatuses in this systems. The tracking apparatus is the system of electromechanical that the guarantees of radiation of solar energy is constantly opposed for maximizing harnessing of energy to the outer of the cells of photovoltaic or solar [6].

Photovoltaic, solar architecture, solar heating, solar thermal energy, artificial photosynthesis and molten salt power plants are the ever-evolving technologies which harnessed employing a range through radiant light and warmth of solar energy from the sun. The sun is a source of energy which is endless and boundless. It gives us energy in form of light and heat. Comparing to other renewable energy sources, the source of energy is as good as solar. Other unlike conventional source of energy is so inexhaustible as it. This provides an alternative energy source that is clean, abundant and eco-friendly with no pollution.

The renewable energy sources like solar energy is used to produce power in the form of electricity or heat. Use of solar energy is now increasing day by day, as the reserve of fossil fuel in earth is decreasing day by day and it is most eco-friendly energy source. This probable solution will be fulfilled our energy demand in the severe crisis moment of predictable energy in close to future. Besides it is ecological and non-polluting. Solar energy can be easily used in non-electricity areas in our country, as it is low cost and most versatile source of energy.

Typical solar energy collection system consists of solar panels that are mounted on a fixed structure, which is not very efficient. A solar panel converts maximum amount of solar energy into electricity when it is perpendicular to the sun position [7]. But in a fixed system that is only possible once a day only. So, this tracking systems are more important to know about the location of sun's and position of the panels of solar. To know the position of sun during the day, this solar system will be built in the tracking system with a dual axis and move the position of solar panels accordingly so that the panels stay perpendicular to the sun. Here our project objectives are -

i. To provide basic information about solar energy and solar panels.

ii. To provide a low cost, eco-friendly and efficient solar panel system.

iii. To employ the solar energy in a maximum value over solar panel to track the sun.

iv. To as semble DC gear motor control circuit interfaced with driver circuit.

v. Design a prototype model of solar cell movement system with a mechanical assembles to move the panel towards the sun.

vi. To harness a clean energy to save our limited and non-renewable energy sources like fossil fuels.

\section{LITERATURE REVIEW}

This sun tracking system is designed to capture maximum solar energy available throughout the day at lowest cost possible. This system uses Light Dependent Resistor (LDR) as the light sensor.

Whenever an LDR gets shadow, its resistance increases and signal is sending by the microcontroller to the gear motor and turns the solar panels at a position where all LDR resistance are same, which is directly towards the sun. We also know that the sun position changes to north to south due to seasonal variations. That's why we designed the system as dual axis tracking system. This system also consists of a real time clock IC. Using this clock IC, the system resets its position at a given time set by the user. 


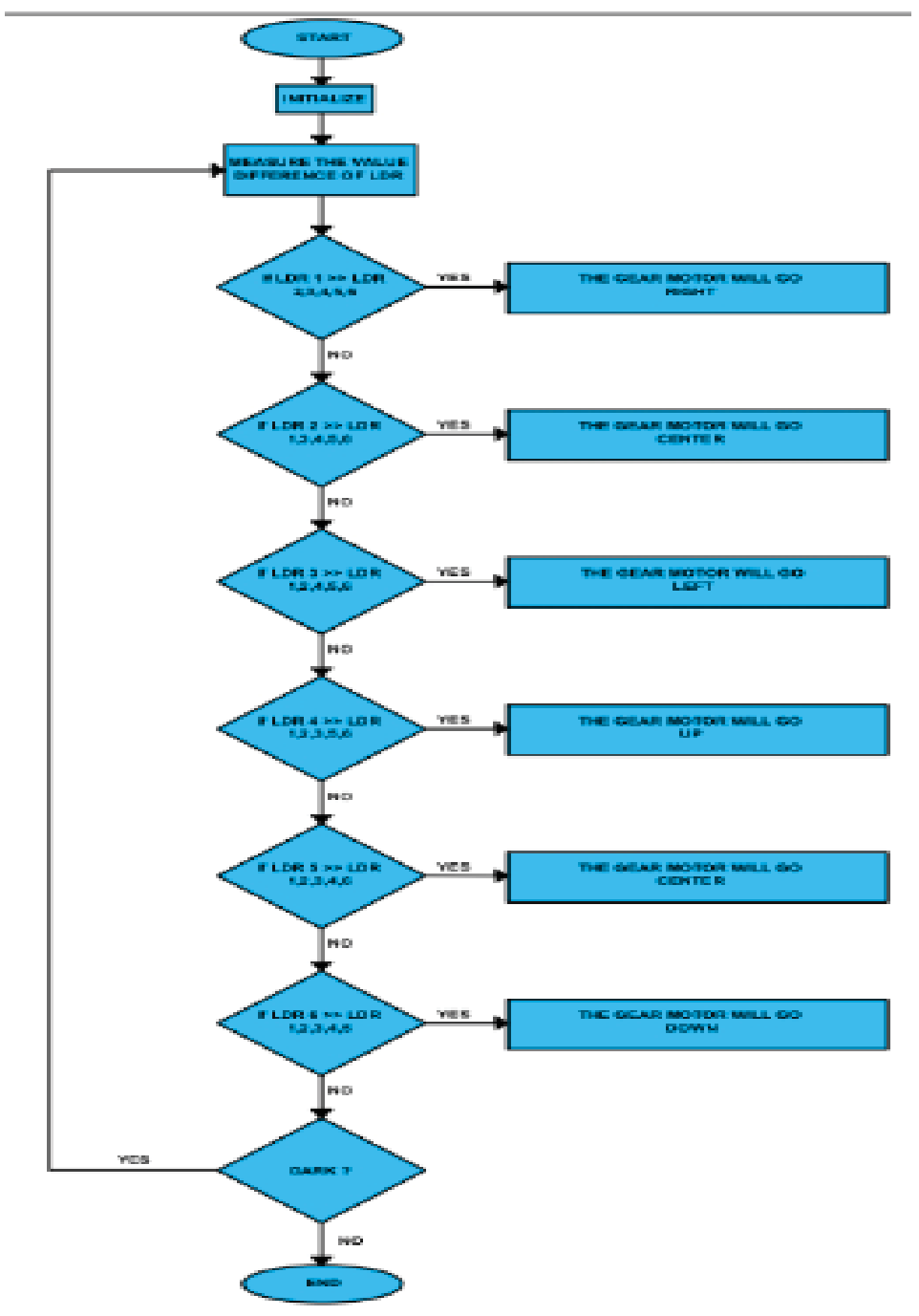

FIGURE 1. Main flowchart of microcontroller programming

The process of designing a sun tracking solar system involves the theoretical completion of a number of subsystems to make the capability of solar energy convert to electrical energy. Various factors inhibited this process. The economic feasibility of the design is the most notable. If the designed of tracking system is able to construct more energy at lesser cost than the fossil fuels and conventional solar energy collection system, then the economically possible project is deemed. 


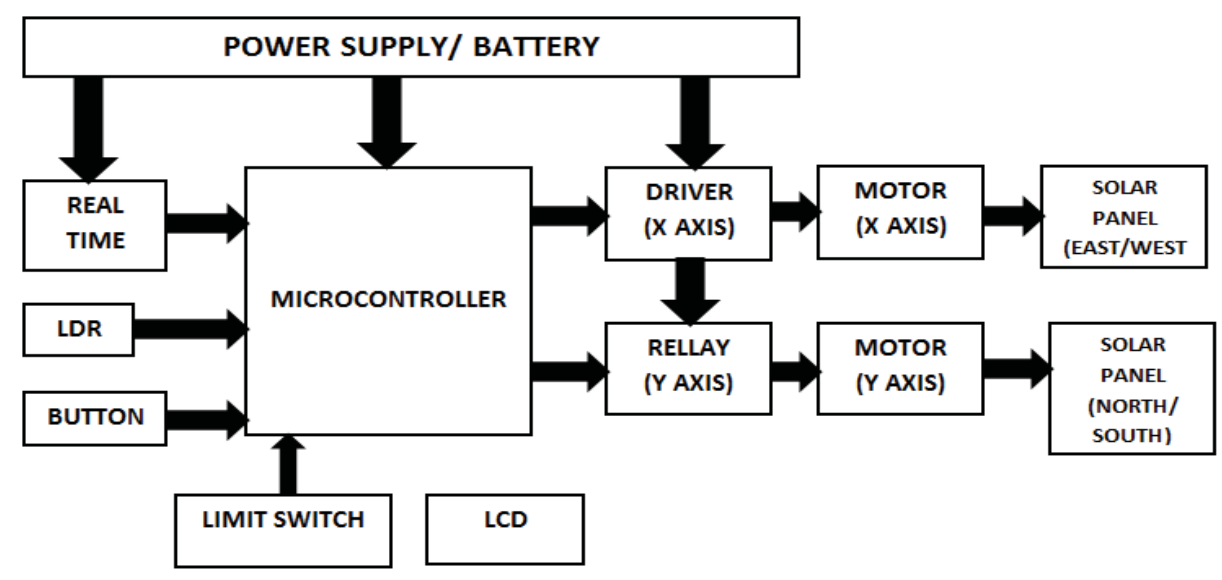

FIGURE 2. Block diagram of the sun tracking panel of solar

\section{HARDWARE DESIGN}

The time-based design of sun tracking solar system of project consists of Solar Panel, Light Dependent Resistor, Gear Motor (east-west movement), Gear Motor (north-south movement), Display, Microcontroller - PIC16F876, Relay - 12v DC 5 pin, Motor Driver - L298.

The fig-2 shows the complete circuit diagram of the time-based sun tracking solar system

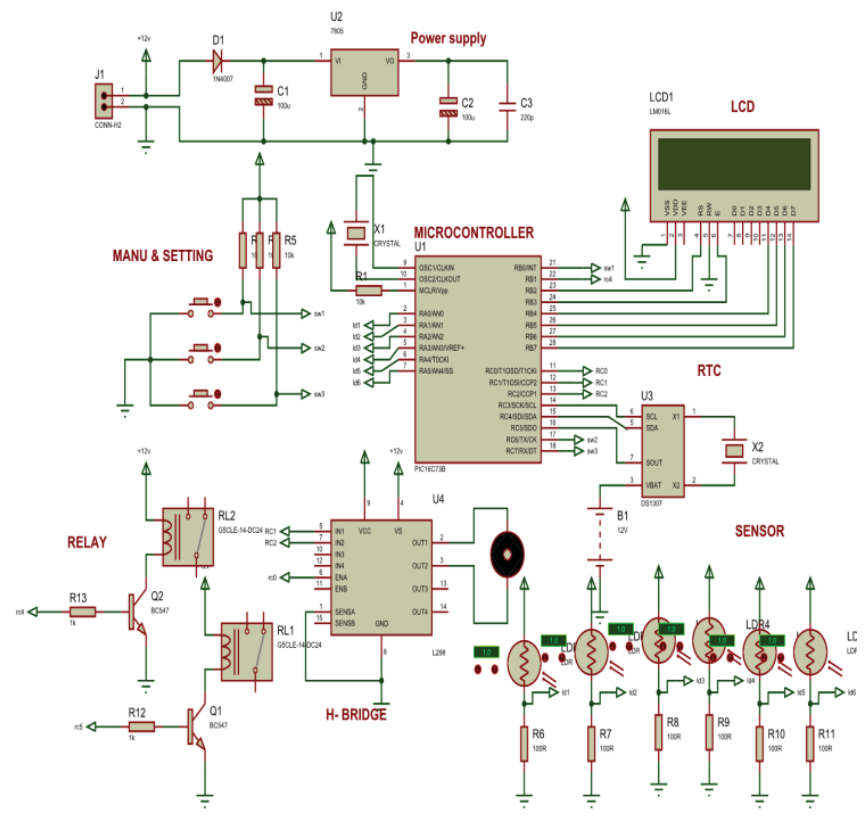

FIGURE 2. Circuit Diagram of the system

\section{A. Solar Panel}

A cell of photovoltaic or solar is an electrical equipment which transforms the light energy with photovoltaic effect directly into electricity. This phenomenon is chemical and physical also. An electrical characteristics device characterized which is a type of photoelectric cell for example, voltage, fluctuate, current, or resistance while 
presented to light. A form of modules combined to construct an individual solar cell, contrarily it is considered to know as Solar panels. Here in our project, we considered 10-watt Solar Panels.

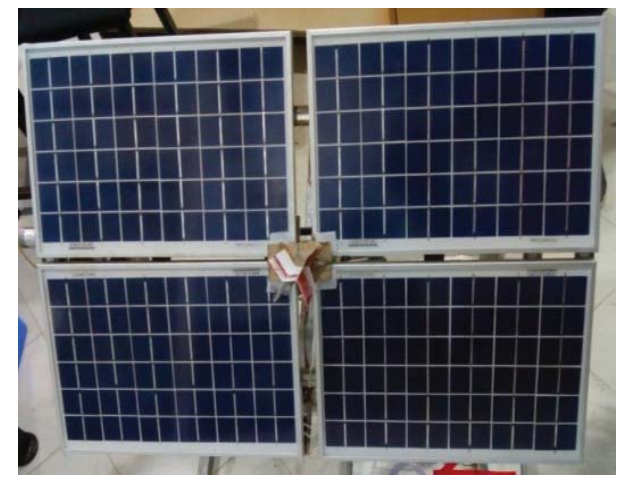

FIGURE 3. Block diagram of the sun tracking solar panel

\section{B. Gear Motor}

A gear motor is a particular sort of electrical motor that is intended to deliver high force or torque while keeping up a low horsepower or low speed. Gear Motor can be found in a wide range of uses, and are utilized in numerous devices in our home and industries.

Gear motor are generally utilized in devices, for example, can openers, garage entryway openers, time control knob of the washing machine, and even electric alarm timers. Regular commercial us es of gear motor incorporate clinic beds, commercial jacks, cranes and numerous different applications that are beyond any reasonable amount to list. We utilized two distinctive gear motor which is a couple to a movable structure with the solar panel boards mounted on that structure.
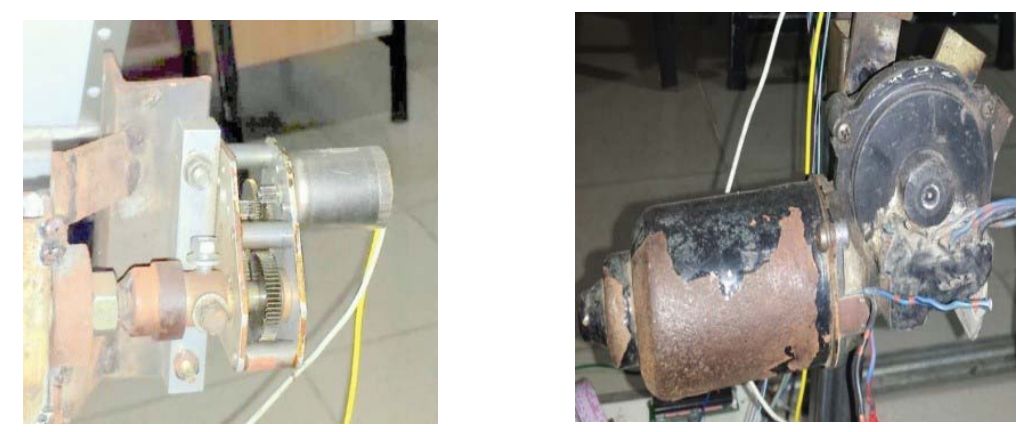

FIGURE 4. Type-1 (east-west movement) and Type-2 (north-south movement)

\section{Microcontroller}

A microcontroller is a minimized incorporated circuit intended to oversee a particular activity in an embedded system. An ordinary microcontroller consists of a processor, memory, and input/output (I/O) peripherals on a single 
chip. Some of the time introduced as a microcontroller unit (MCU) or an embedded controller. Microcontrollers are found among various devices in cars, robots, office machines, clinical equipment, portable radio handsets, sales machines and home appliances. In our project, we considered using the PIC16F876 microcontroller for our system.

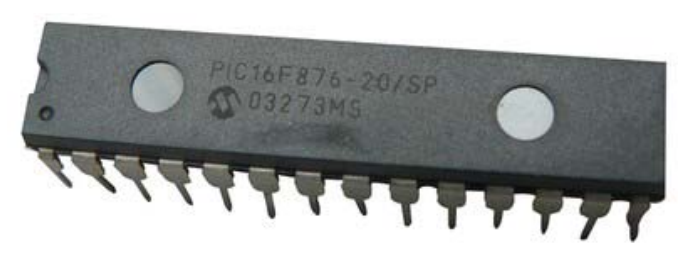

FIGURE 5. Physical overview of PIC6F876 M 1icrocontroller

\section{Motor Driver}

A motor driver is a small current amplifier; motor drivers have the purpose of taking a low-current control signal and then converting it into a higher-current signal which can drive a motor. We used L298 motor driver for our system.

\section{E. Relay}

A Relay is an electrically operated switch that mechanically controls the switch using an electromagnet. Relays are used in different application including automobiles, industrial automation among others. We used two $12 \mathrm{v}-5$ pin DC relay for the motor which moves the solar panels to north-south.
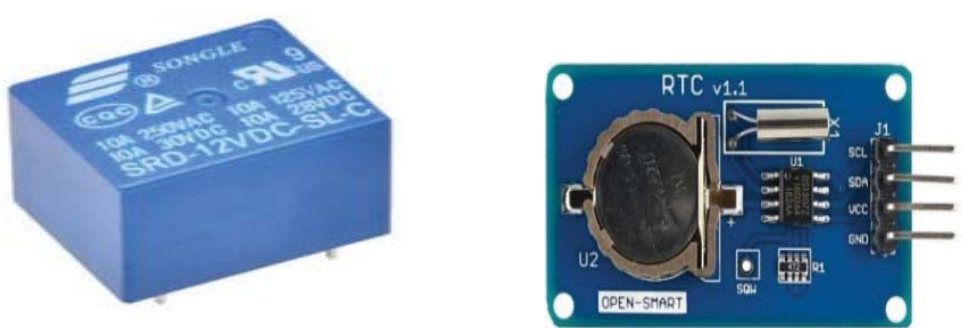

FIGURE 6. Physical overview of Relay and RTC

\section{F. Real Time Clock (RTC)}

In electronic circuits Real-time clock (RTC) ICs are used to keep track of time relative to the "real " world. Maintaining accurate time is crucial, particularly in periods of severe system stress or when the main device's power is off. RTCs are present in almost any electronic device which needs to keep accurate time. We used DS1307 RTC IC for our system. 


\section{G. Battery}

In our project we used a $12 \mathrm{v}, 7.5 \mathrm{AH}$ battery. It functions as the storage device for the electrical energy collected by solar panels and as the power supply for the tracking system.

\section{HARDWARE AND RESULT ANALYSIS}

The concept of this tracking device is to install 4 solar panels on a platform. It will watch the sun during the day, with the panels installed. The panel will rotate in 4 directions. The machine support base is a square base which helps support the whole weight. One of the benefits of the design is that the layout needs little room for activity . Another advantage is that the structure is portable.

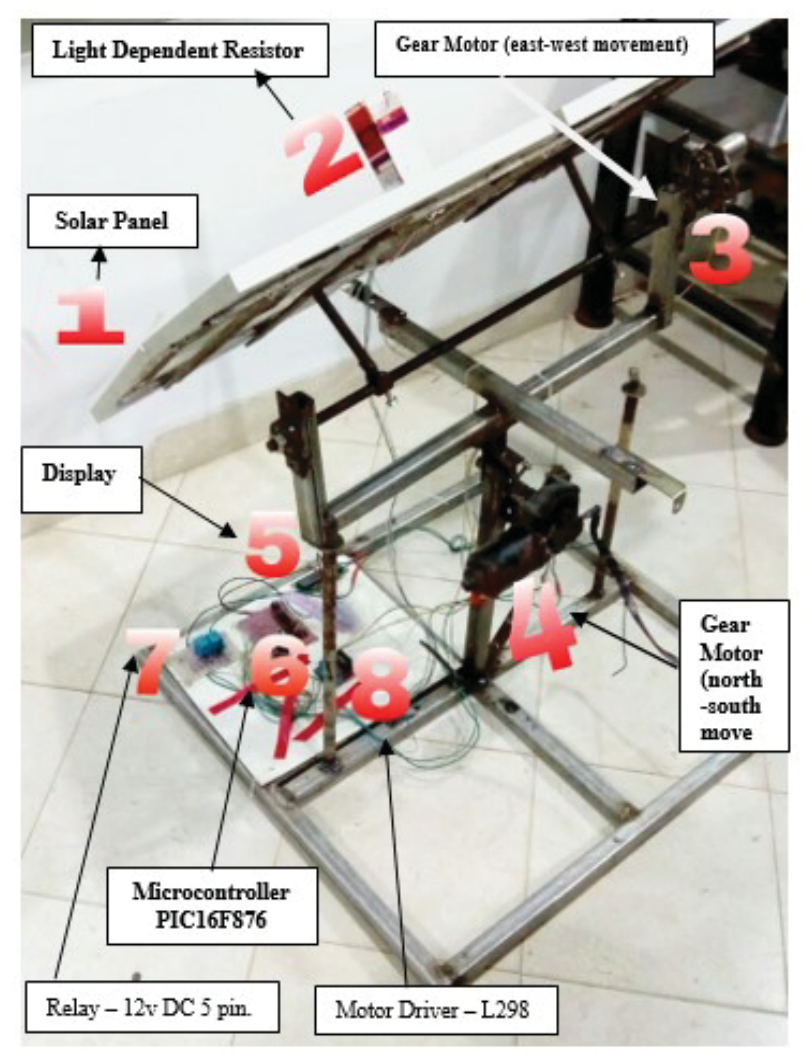

FIGURE 7. Physical overview of Sun Tracking Solar System

For better understanding, video of the project may help to realize the project. But in a paper, it is not possible to add a video. So that, we have made a video and uploaded in YouTube [8]. One can watch this to understand how this system really works.

\section{CONCLUSION}

Demand of energy is increasing day by day. To keep up with this demand we are exhausting our resources like fossil fuels. But soon the reserve of fossil fuels in the earth will be depleted. So, the world is turning to natural and renewable resources for energy. Solar power has been at the top of the renewable energy resources list for a long time. But the conventional system is fixed solar panels. The efficiency of these fixed solar panels is low. By using 
the tracking system, we implemented in our project, the efficiency of the panels and the power output can be increased significantly. Not only it will reduce pressure on fossil fuels but also it will help our planet to recover from pollution and reduce emission of greenhouse gases that are damaging the ozone layer. Moreover, it will reduce cost on our electricity bills.

\section{REFERENCES}

[1] G. Deb and A. B. Roy, "Use of solar tracking system for extracting solar energy," International Journal of Computer and Electrical Engineering, vol. 4, no. 1, pp. 42-46, 2012.

[2] T. Tudorache and L. Kreindler, "Design of a solar tracker system for PV power plants," Acta Polytechnica Hungarica, vol. 7, no. 1, pp. 23-39, 2010.

[3] Ferdaus, R.A.; Mohammed, M.A.; Rahman, S.; Salehin, S.; Mannan, M.A. Energy Efficient Hybrid Dual Axis Solar Tracking System. J. Renew. Energy 2014.

[4] K. Liu, "Dynamic characteristics and graphic monitoring design of photovoltaic energy conversion system," WSEAS Transactions on Systems, vol. 10, no. 8, pp. 239-248, 2011.

[5] H. Mousazadeh, A. Keyhani, A. Javadi, H. Mobli, K. Abrinia, and A. Sharifi, "A review of principle and suntracking methods for maximizing solar systems output," Renewable and Sustainable Energy Reviews, vol. 13, no. 8, pp. 1800-1818, 2009.

[6] M. Benghanem, "Optimization of tilt angle for solar panel: Case study for Madinah, Saudi Arabia," Applied Energy, vol. 88, no. 4, pp. 1427-1433, 2011.

[7] Kaur, Amandeep \& Chhetri, Goma \& Singh, Narinder \& Asif, \& Kumar, Sunil \& Channi, Harpreet Kaur. (2017). Designing of Solar Tracking System using AT89C51 Microcontroller. 10.13140/RG.2.2.20691.27685.

[8] Rocky Ali. CHT Project Home. Retrieved August 02, 2020, from https://youtu.be/d9CDCGMNh6s

[9] S. S. Mahtab, M. J. Alam, A. M. Khan, Z. Uddm, A. A. Mamun and M. M. Uddin, "Optimization of InSb QWFET layer structure for high-speed and low power nano electronics applications," 2017 4th International Conference on Advances in Electrical Engineering (ICAEE), Dhaka, 2017, pp. 707-711, doi: 10.1109/ICA EE.2017.8255447. [Publisher: IEEE]

[10] S. S. Mahtab, A. Monsur, S. S. Ahmed, R. Chakma and M. J. Alam, "Design and Optimization of Perovskite Solar Cell with Thin ZnO Insulator Layer as Electron Transport," 2018 International Conference on Advancement in Electrical and Electronic Engineering (ICAEEE), Gazipur, Bangladesh, 2018, pp. 1-4, doi: 10.1109/ICA EEE.2018.8643012. [Publisher: IEEE]

[11] S. S. Mahtab ,M. A. Hossain., "Efficient and Stable Perovskite Solar Cell with TiO2 Thin Insulator Layer as Electron Transport," 2019 International Conference on Robotics,Electrical and Signal Processing Techniques (ICREST), Dhaka, Bangladesh, 2019, pp. 54-58, doi: 10.1109/ICREST.2019.8644093. [Publisher: IEEE]

[12] R. Chakma ,S. S. Mahtab., "Navigation and Tracking of AGV in ware house via Wireless Sensor Network," 2019 IEEE 3rd International Electrical and Energy Conference (CIEEC), Beijing, China, 2019, pp. 1686-1690, doi: 10.1109/CIEEC47146.2019.CIEEC-2019589. [Publisher: IEEE]

[13] M. F. S. Khan, S. S. Mahtab., "PLC Based Energy-Efficient Home Automation System with Smart Task Scheduling," 2019 IEEE Sustainable Power and Energy Conference (iSPEC), Beijing, China, 2019, pp. 35-38, doi: 10.1109/iSPEC48194.2019.8975223 [Publisher: IEEE]

[14] Ismail Siddiqi Emon, Sabiha Sunjida Ahmed, Sharmin Akter Milu, and S. S. Mahtab. 2019. Sentiment analysis of bengali online reviews written with english letter using machine learning approaches. In Proceedings of the 6th International Conference on Networking, Systems and Security (NSys S 19). Association for Computing Machinery, New York, NY, USA, $109-115$. DOI:https://doi.org/10.1145/3362966.3362977

[15] Milu S.A. et al. (2020) Sentiment Analysis of Bengali Reviews for Data and Knowledge Engineering: A Bengali Language Processing Approach. In: Bindhu V., Chen J., Tavares J. (eds) International Conference on Communication, Computing and Electronics Systems. Lecture Notes in Electrical Engineering, vol 637. Springer, Singapore. https://doi.org/10.1007/978-981-15-2612-1_8

[16] Ahmed S.S., Milu S. A., Emon I. S., Mahtab S. S. (2020) Opinion Mining of Bengali Review Written with English Character Using Machine Learning Approaches. In: Bindhu V., Chen J., Tavares J. (eds) International Conference on Communication, Computing and Electronics Systems. Lecture Notes in Electrical Engineering, vol 637. Springer, Singapore. https://doi.org/10.1007/978-981-15-2612-1_5 
[17] Jahan Buurat, Mahtab S. S. , Milu S. A., Emon I. S., (2020) An Automated Bengali Text Summarization Technique Using Lexicon Based Approach. In: International Conference on Innovations in Computer Science and Engineering (ICICSE-2020). Springer "Lecture Notes in Networks and Systems"

[18] Jahan Buurat, Mahtab S. S. , Milu S. A., Emon I. S., (2020) A Pronoun Replacement Based Special Tagging System for Bengali Language Processing (BLP) In: International Conference on Innovations in Computer Science and Engineering (ICICSE-2020). Springer "Lecture Notes in Networks and Systems"

[19] Fazlul Hoque, Rocky Chakma, S. S. Mahtab, Rupa Akter , Sabiha Sunjida Ahmed "Design and Developing Real Time Interactive IIUC Bus Tracking System":, Journal of Innovation in Computer Science and Engineering" (JICSE) with ISSN 2278-0947 in Volume 9(2), Volume 10(1) 